3) At present the Canadian Historical Association and the Canadian Political Science Association represent the research community on the Advisory Council on Public Reconds. The Public Archives is giving serious consideration to widening the diversity of representation of the research community.

4) The full text of Part IV of the Canadian Human Rights Act can be found as an appendix to the 1980 Index of Federal Information Banks which is available for reference in every Post Office and Canada Manpower Office across Canada.

5) Kissinger vs Reporters Comminee for Freedom of the Press et ol.. Supreme Court of the United States, March 3. 1980, No 78-1088 and 78-1217. The case involved summary or verbatim transcripts of Kissinger's conversation notes and telephone notes which he "unlawfully removed" from the State Department and at a later date deposited at the Library of Congress with severe access restriction. In short, the Supreme Court ruled that the plaintiffs had "no standing" and that only the National Archives and Records Service and/or the State Department could pursue Kissinger for return of the notes.

6) Senate Report to the Federal Records Act of 1950. S. Rep. No. 2140,81 st Congress, 2nd Session, at 4(1950).

7) The distribution of SIN numbers by first letter of sumames for $R$ is $4.94 \%$. The author is currently undertaking a project to establish an overall mixed numeric-alphabetic sampling scheme for case files falling under privacy legislation. This includes a study on the distribution of first letters of surnames of language. ethnic and provincial groupings.

\title{
THE CONDUCT OF USER SURVEYS
}

\author{
Dennis D. McDonald, Ph.D. \\ King Research, Inc \\ Washington, D.C.
}

l'd like to start by making a few statements in general about user surveys, and then to discuss their goals. their different varieties, and finally some methodological pointers

First, there's no such thing as an "end user."

Second, information isn'l a commodity like a bas of soap which can be bought, sold, and priced "over the counter."

Third, don't believe that users and potential users can tell you pointblank what they really want and need in the way of information services.

Finally. the more you know about a user before you conduct a user survey, the better off you'll be

\section{GOALS}

User survey goals can be classified into the following five categorie:s:

\section{- Input prior to system development.}

You may want to find out the needs of a potential user group before you invest a lot of dollars in the development of systems or services. This kind of user survey is difficult to conduct since what people say they may need and what they actually end up using may be two entirely different things

\section{- Information about your competition.}

You may be in the process of developing a system or service, and you may want to assure yourself that related information products and services, i.e., your "competition," are not satisfying the same needs. This kind of survey is essentially a form of intelligence gathering. and conducting it will force you to consider how your product or service will supplement what is already available.

\section{- Identity of current users.}

You may have a system in operation. and you may want to find out not only how and why people are using your system, but whether they are satisfied with what your system is supplying. This is what most people consider to be a "user survey."

\section{- Potential users.}

You may have a system which is operaling and satisfying the needs of a certain core group of users But you want to expand the system's use. You must then seriously think about potential user populations and how to ash 
them about their own needs and what information sources they currently use. I recommend, however, that you conduct a survey of potential users either after or concurrent with your survey of current users. Otherwise. you may never understand the context within which your current users operate and this will hamper your ability to promote your system to new users

\section{- Evaluation.}

You may want to evaluate a system by means of a user survey. In fact, surveys are often conducted as an input to evaluating many kinds of systems and services, in addition to those devoted specifically to information services. But it is wise to remember that a survey is not, in and of itself, an evaluation method; it is simply a tool of evaluation, and the actual evaluation depends upon how the results of the user survey are interpreted.

Each of these five goals is related to the different kinds of user survey you might conduct. And accomplishment of these goals is also related to the four points I made earlier.

1 mentioned, for example. that "there is no such thing as an end user." The term "end user" implies a certain finality, as if the information your system supplies converges at one point and "sits there," like the "stop" symbol in a flowchart. If you think about the people who have access to your products and services, you probably hope that the information you supply do sn't stop with them. Ultimately, you want it to affect therr thinking and behavior. One of their potential behaviors is sharing the information you supply with others, periaps in a substantially modified form (This can also feed back into increased use of your services through "word of mouth" advertising) So when you survey your users you want to know not only what they do with the information they obtain; you should also find out how they retransmit this information, and to whom they retransmit it. (This is a practical way of identifying potential users.)

1 also mentioned that information isn't a commodity, like a bar of soap. This also affects the goals you can accomplish through a user survey. For example, two of the most important questions you will ask when developing or modifying your system are "How much are people going to use it?" and "How much are they willing to pay to use it?" If you are developing a database which will be accessed online, you may need to address yourself to two groups: the people who sit at the terminal and interact with the system, and the people who actually use the output of the online interaction; these two groups are not always the same. The kinds of questions you ask these two groups may be substantially different. The first group you will want to ask about their interaction with the system and how they relate to their users. The second group, the actual users, you'll want to ask what they do with the information they obtain from the system. If both of these groups have no experience with the type of system by which your database will be accessed, asking them hypothetical questions about amount of use and willingness to pay may very well be counterproductive. You would do much better to ask them about the types of decisions and problems they have to face on a day-to-day basis. Since information is only one of the resources people use to solve problems and make decisıons, a detailed understanding of these problems - what some people call the "situational context" - will be useful.

\section{KINDS OF SURVEYS}

Given the relationship between the user survey goals and the types of questions which you might focus upon in your user survey, several different kinds of surveys begin to emerge

The first kind of user survey is the one which concentrates on the user's interaction with the system. Here the types of questions concern such things as:

- Frequency of access

- Type of access channel

- Payment for use

- The nature of the access system

- The physical medium used to supply the information

- The ease with which the system can be accessed

- Reasons for satisfaction and frustration with the system

The second kind of user survey concentrates on the information which is supplied by the system. Here the relevant questions are:

- The type of problems or decisions which are important to the user

- The role information plays in solving these problems

- The relative use of different information sources for solving these problems

- The perceived accuracy and reliability of these information sources

In the real world, it's impossible in a user survey to completely scparate reactions to (1) the contents of a database from (2) the system used to obtain access to the contents. since the two are so often intertwined. The perfect example of this is the system which allows the user to manipulate a database using a very flexible, personalized command language. Essentially, the user is generating a unique product each time he or she sits down in front of the terminal. In this case. the actual contents of the database may take secondary importance to the way in which the user interacts with the system, since it may be the interaction method which makes the system unique.

\section{METHODOLOGICAL POINTERS}

Now, l'd like to discuss some methodological points related to user surveys. These deal with three main issue areas:

- How the survey should be conducted

- How the sample is designed

- How the questionnaire is designed 
One assumption I make is that a survey, by definition, involves the collection of a standardized set of data elements from a group of individuals. A further assumption is that data collection may involue an interaction with geographically. dispersed individual users, instead of, for example, direct observation of their behavior

Concerning sample design, by far the most important issue is how best to define and identify a population of users from which to sample. Sample size is not, as may be commonly believed, the major issue. The major issue is ensuring that you contact the right people, the people who are qualified to answer the questions you have. The more time and effort you devote to sample development, the more will be your reward. Some of the practical implications of this view are the following.

First, while it is cheaper to purchase a list of individuals' names and addresses from a commercial list supplier or professional association. you may be better off if you develop your own list, perhaps over time, of people who have used or who have expressed an interest in your system. (This, of course, will not be sufficient for studying all potential users.)

Second, try to obtain complete information on the type of organization which employs your system's potential user. Prefer the devlopment of lists with business address, rather than home address. That way you can subdivide or stratify your sample by employer type before you conduct your survey.

As a general rule, try to settle upon the specific population whose ise you will be studying before you draft your questionnaire. That way you can be sure that the questions you want to ask are appropriate for your sample, and vice versa.

Never assume that your users are thoroughly familiar with your information center or system; always describe in detail the system or service whose use you are studying Remember, your system is only one of the information sources your user relies upon.

Be sure to allow your user in the survey to give some indication of frequency of use. You will want to divide your analysis into "frequent users" and "infrequent users"; their preferences may differ significantly.

Approach "willingness to pay" questions with great caution. Many individuals are not accustomed to paying directly for information services. The person whom you want to ask about payment questions may be the business officer or administrator with sign-off responsibilities, not the assistant researcher who will not be paying you directly.
Be prepared to define and explain your questionnaire terms in great detail. This is especially true when you are dealing with information products and services. Terms such as "information," "access," and "use" must be defined concretely if you are to have confidence in your analysis. It's because of the need to provide extensive definitions that I am partial to self-administered mail questionnaires, since they allow the researcher to provide supporting definitions and instructions while being cheaper than personal interviews.

Be sure to pretest your questionnaire with respondents who are similar to the ultimate survey respondents. You'll be surprised how much pretest respondents may misinterpret your questions and response categories.

Be sure to involve your programmer in questionnaire design. There is nothing more frustrating than finding you can't analyze a question in a particular way since the coding and editing were done after the questionnaire was filled out

Devote resources to following up and increasing your response rate. If it comes to a tradeoff between spending time and money on increasing the initial sample size, and spending time and money to follow up your initial mail-out sample, go with the latter

Try to avoid designing questionnaires by committee, and set a definite limit on the number of questionnaire revisions you can tolerate. Remember that no questionnaire is perfect, since no two individuals are alike and they will want to make exceptions no matter how detailed your planning is.

Finally, always allow respondents in your survey the opportunity to express themselves in their own words, even if the questionnaire is substantially pre-coded; you will be surprised how valuable individual handwritten comments can be, especially when thay suggest potential uses and benefits of your system which you may have overlooked.

\section{CONCLUSION}

The most important secret to conducting a good user survey cannot be described in methodological terms. Excellent sampling. proper questionnaire wording, mistake-free survey processing, and sophisticated analysis cannot overcome an incomplete or limited understanding of the product or service whose use you are measuring. Be sure to ask yourself why you are conducting the survey. If you seriously try to answer this question before you start out you will go a long way to makıng sure that your survey helps you answer your mosi important questions. 